\title{
Satellite remote sensing-based detection of the deformation of a reservoir bank slope in Laxiwa Hydropower Station, China
}

\section{$\operatorname{AUTHOR}(\mathrm{S}):$}

Zhang, Dexuan; Wang, Gonghui; Yang, Tinjun; Zhang, Mingchu; Chen, Shihang; Zhang, Fanyu

\section{CITATION:}

Zhang, Dexuan ... [et al]. Satellite remote sensing-based detection of the deformation of a reservoir bank slope in Laxiwa Hydropower Station, China. Landslides 2013, 10(2): 231-238

\section{ISSUE DATE:}

2013-04

URL:

http://hdl.handle.net/2433/173359

\section{RIGHT:}

The final publication is available at www.springerlink.com; この論文は 出版社版でありません。引用の際には出版社版をご確認ご利用くださ $\omega_{\circ}$; This is not the published version. Please cite only the published version. 


\title{
Satellite remote sensing based detection of the deformation of a reservoir bank slope in Laxiwa Hydropower Station, China
}

Dexuan Zhang · Gonghui Wang( $\triangle$ ( ) Tinjun Yang · Mingchu Zhang · Shihang Chen · Fanyu Zhang

\author{
Addresses of authors: \\ Dexuan Zhang \\ Department of Civil Engineering \\ Shanghai Jiaotong University \\ Shanghai 200240, P.R. China
}

Gonghui Wang (corresponding author

Disaster Prevention Research Institute

Kyoto University,

Uji, 611-0011, Kyoto, Japan

Email: wanggh@landslide.dpri.kyoto-u.ac.jp

Tinjun Yang

Northwest Hydro Consulting Engineers

No.18 East Zhangba Road 710065

Xi'an, P.R. China

Mingchu Zhang

University of Shaoxing

No.5 Huancheng West Road, 312000

Shaoxing, P. R. China

Shihang Chen

Shanghai Maritime University

1550 Pudong Dadao, Shanghai, P.R. China

Fanyu Zhang

School of Civil Engineering and Mechanics

Lanzhou University

Tianshui Road, Lanzhou, 730001

P.R. China 


\title{
Satellite remote sensing based detection of the deformation of a reservoir bank slope in Laxiwa Hydropower Station, China
}

\author{
Dexuan Zhang • Gonghui Wang • Tinjun Yang • Mingchu Zhang • Shihang Chen • Fanyu Zhang
}

\begin{abstract}
Laxiwa Hydropower Station is the largest one among those hydropower stations in the upper reaches of the Yellow River. The construction was started in October 2001, diversion tunnel was finished in January 2004, and impoundment started in March 2009. However, from May 2009, the right-bank slope of the reservoir about $700 \mathrm{~m}$ high and $1000 \mathrm{~m}$ wide located $500 \mathrm{~m}$ far from the dam was found to be deforming greatly and continuously. Although this slope had been identified as an old landslide, the survey before the construction of the dam concluded that this slope being composed of granite is stable and would be stable even after the impoundment, and then no detailed monitoring of the slope deformation had been performed before the visible deformation occurred after the impoundment. To indentify the relationship between the deformation of the slope and impoundment, we utilized D-InSAR and ALOS Prism to analyze the slope deformation before and after impoundment. We found that there was no identifiable deformation before the impoundment, and the maximum horizontal displacement reached approximately 7.5m during the period of 3 April 2009 to 22 May 2010 after impoundment. This slope is still deforming even after a total horizontal displacement of several tens of meters being reached, showing high risk of catastrophic landsliding.
\end{abstract}

Keywords: Remote sensing - D-InSAR - ALOS Prism - Hydropower Station - Slope deformation • Impoundment

\section{Introduction}

The instabilities of bank slopes induced by reservoir impoundment have been a key issue in the construction of dams, because they can not only affect the function of the dams, but also result in great disaster to the wide area downstream the dam. For example, the catastrophic failure of the left bank slope occurring in Vajont Reservioir resulted in more than 2600 casualties (Muller, 1964). Although the instability problem of bank slopes had attracted great concern since the Vajont event, they are still a challenging problem. This can be examplified by the construction of the Three Geogres Dam in China, in which 430 landslides had been triggered, 5386 other potentially dengerisou sites had been identified and are being monitored. These landslides costed billions in monetary losses, and also forced another 100,000 people to move. Further, a big landslide reactivating on the upper stream of the dam of Laxiwa Hydropower station, which is very similar to the case of Vajoint dam and will be introduced in this paper, is direactly threatening the safety of the dam and people living downstream.

Laxiwa Hydropower Station is a very large hydropower station on the main reach of the Yellow River, which is still under construction. It locates between Guide County and Guinan County, Qinghai Province, about $134 \mathrm{~km}$ far from Xining City, Qinghai Province (Fig.1). The dam has a $250 \mathrm{~m}$ high concrete double-curvature arch dam with its crest length being about $460 \mathrm{~m}$. The primary purpose of the dam is hydroelectric power generation and it is designed to support a $4200 \mathrm{MW}$ power station. The normal reservoir water level is $2452 \mathrm{~m}$, dead water level is $2440 \mathrm{~m}$, the total reservoir capacity is about 1.08 billion $\mathrm{m}^{3}$, and the active reservoir capacity is 0.15 billion $\mathrm{m}^{3}$. 
The preparation for the construction of Laxiwa Hydropower Project started in October 2001. In January 2004, the Yellow River was diverted and in September of the same year, excavation on the dam's abutment was started. In April 2006, the first concrete was cast and on March 1, 2009, impoundment began. On May 18, 2009, the first two electric generators were put into function.

In late May 2009 (soon after the impoundment), the right-bank slope (Guobu slope) 500 m upstream of the dam showed remarkable deformation (Fig. 2): cracks appeared and kept widening on the crest of the slope, and frequent rockfalls occurred. After that a deformation-monitoring network was installed urgently, and the deformation of the slope was monitored. For the monitoring, various techniques had been employed. For example, airborne topographic laser scanner was used to obtain topography of the crest and the slope with high precision; 39 observation points were newly setup on the slope for direct measuring by using a total station; 6 boreholes were drilled and 5 new exploration tunnels were dug into the slope to identify the potential sliding surface. It is noted that the borings could not be drilled as designed due to the deforming landslide mass. All the monitored results revealed that the slope is deforming greatly and continuously. Because the deforming slope is about $700 \mathrm{~m}$ high and $1000 \mathrm{~m}$ wide in average, and is very close to the dam site, if slope collapse would occur, it could greatly damage or destroy the dam and all other facilities. Besides, the possible wave will flood the downstream area, greatly threatening people living there and downstream hydraulic schemes. Namely, disaster similar to the 1993 Vajont catastrophe (Kiersch 1964; Moller 1964; Skempton 1966; Semenza and Ghirotti, 2000; Genevois and Ghirotti 2005; among others) could occur.

Although the deformation of the slope has been monitored precisely and continuously since the impoundment, there were no data on slope deformations before the impoundment., The sliding surface has not been identified yet though survey in boreholes and tunnels has been performed. Thus, study of possible developing history of this landslide as well as spatial information of the slope deformation will be of great importance to understand the initiation mechanism of instability and to provide proper countermeasures for lowering or excluding risk of slope failure. For this purpose, satellite remote sensing technology might be a proper approach, because (1) it can cover wide areas and monitor the target area periodically; and (2) some parts of the slope in question are not accessible at present and are dangerous for working there due to the rapid deformation. Therefore, we used interferometric analysis of synthetic aperture radar (InSAR) and of satellite optical images with very high-resolution to grasp the possible deforming areas and to analyze the ground displacement level.

\section{Overview of Guobu slope}

Guobu Slope is located at the right bank upstream from the Laxiwa Hydropower station, 500-1700 m from the dam. The V-shaped valley here is narrow with steep slope. At the toe part of the slope, the water surface is $2254 \mathrm{~m} \sim 2257 \mathrm{~m}$ above sea level and the slope angle ranges from $38^{\circ}$ to $46^{\circ}$. The bedrock of the dam site area is Mesozoic granite (Fig. 3), and Guobu slope was thought to be stable being composed of granite, although it is very high and steep. Nevertheless, the stepped topography on the crest of the slope indicates that Guobu slope might be an old deep-seated landslide or sackung. Fig. 4a shows some photos of a wider view of the whole area from Google earth that was based on the satellite images of May 18, 2004, while Fig. 4b and Fig. 4c show the photos of the crest that were taken at different years before the impoundment. The crest of Guobu Slope is a 
triangular in plan view and relatively flat 'terrace', $750 \mathrm{~m}$ long and 50 290 m wide at 2930 2950 m a.s.1., 700 $\mathrm{m}$ above the river bed. It is bounded by a distinct scarp, and talus can be seen in two areas outlined by the red cycle and white box in Fig. 4a.

Presence of the ancient landslide at this slope had been identified during the survey time before the construction, and detailed geological surveys had been conducted since 1989. Four simple observation piles had been set from 1991 to 1997 to monitor the displacement of slope. But no obvious displacement had been recorded. On the other hand, no visible cracks or deformation could be identified on the crest during the period of 1989-2003 (i.e., before the impoundment) (Fig. 4a-c).

The impoundment began on March 1, 2009, and some tension cracks were found on the crest of Guobu slope in early June, accompanying with the occurrence of some small-scale rockfalls on different parts of the slope. Detailed monitoring of the slope started in August 2009, and the data showed that the whole slope was deforming significantly and continuously with the increase of the reservoir water level. Some monitoring points indicated a daily displacement of several centimeters, and the total displacement in five months reached several meters. It is noted that we are not allowed to show detailed monitoring results at present, but those will be available after successful countermeasures had been performed. Nevertheless, scale of the displacement can be briefly understood through the subsidence appearing on the crest of the slope, which can be identified even from some photos shown in Fig.5. Fig. 5a shows a close view of the crest that was taken on 12 March 2010, where the cliff had an elevation difference of $20 \mathrm{~m}$. This difference increased to about $26 \mathrm{~m} 7$ months late (Fig. 5b). Due to the great settlement, the development of cliff can even be identified from Google Earth image (Fig. 5c) taken on October 4, 2010.

Fig. 6a presents the topography of the slope area, based on 1:1000 topographical map with the contour interval of $10 \mathrm{~m}$. This map obtained by airborne laser scanner after May 2009. On Fig. 6a, 6 sub-ridges can be indentified on the front slope. Due to the difficulties in the performance of borings and survey tunnels in the deforming landslide body, the location of sliding surface had not been identified yet. Therefore, the sliding surface drawn in Fig.6b is just an inferred one. Considering the depth of the sliding surface, the total volume of the potentially unstable massif is estimated as $120-150 \mathrm{Mm}^{3}-$ about one half of that of the Vajont landslide (Muller 1964; Rinaldo and Ghirotti 2005; Ward and Day 2011).

\section{Satellite remote sensing images}

Differential Synthetic Aperture Radar Interferometry (D-InSAR) is a microwave remote sensing technology based on the Interferometric Synthetic Aperture Radar. Due to its advantage of high-accuracy, high-resolution, all-weather, low-cost and wide-range observation, InSAR becomes very useful in detecting ground movement in continuity large areas, and had been applied to investigate ground deformation induced by earthquakes (Massonnet et al. 1993), volcanoes (Massonnet et al. 1995), land subsidence (Massonnet et al. 1997; Fielding et al. 1998; Galloway et al. 1998; Burgmann et al. 2000), and by landslide activity (for example, Antonello et al. 2004; Singh et al, 2005; Colesanti and Wasowski 2006; Riedel and Walther 2008; Casagli et al. 2010; Yin et al., 2010a, 2010b) . 
Remote sensing images are the basis of monitoring deformation. The investigation and selection of image sources play a key role in the interpretation of images. To fit different types of surface deformation monitoring, appropriate monitoring time and spatial scales should be carefully combined with existing SAR images.

We use interferometric synthetic aperture radar (InSAR) to obtain spatially detailed maps of ground-surface deformation. Two synthetic aperture radar (SAR) images acquired by the European Earth Remote-Sensing (ERS) satellites with a temporal separation of one year or more are compared to analyze their changes in the interferogram. The phases of the signals contain information of coherent displacements of all scatterers imaged by the radar, as well as the information of ground topography.

We checked all the SAR images obtained by ERS from 2003 to present, and found that most of the images are ascending-orbit ones, and no image covered Laxiwa dam site area until late 2007. However, the satellite images taken by the Advanced Land Observing Satellite (ALOS) of the Japan Aerospace Exploration Agency (JAXA) from 2008 to present are available for the dam site area. These ENVISAT images have a resolution of $30 \mathrm{~m}$, whereas the ALOS images have higher resolution. The unipolar PALSAR images have a resolution of $10 \mathrm{~m}$, the images taken by the AVNIR-2 sensor have a resolution of $10 \mathrm{~m}$, and those taken by the PRISM sensor have a resolution of $2.5 \mathrm{~m}$. Considering the available period and the resolutions of these images, we use ALOS PALSAR as the main image source to interpret the radar images (Table 1). ALOS PRISM panchromatic images (Table 2) were used as the image source for interpreting images.

\section{D-InSAR results from ALOS PALSAR images}

We used ALOS PALSAR's high-resolution FBS mode to interpret the images and then analyse the possible deformation of Guobu slope. In this study, we analyzed the slope deformation during two periods (December 2007 June 2008; December $2009 \sim$ February 2010). Table 3 shows the combination and baselines of 4 pairs of images.

For the period of December 2007 June 2008, four images that were taken on December 9, 2007, January, 24 2008, March 10, 2008, June 10, 2008, were used. For the first 3 images, the time interval is 46 days (one revisit cycle) between each of them, and for the last two, the time difference is 92 days ( 2 revisit cycles). For the period of December

2009 February 2010, four images for two pairs were selected and analyzed. One pairs were taken on November 14, 2009 and December 31, 2009 respectively; the other pairs were taken on January 29, 2010 and February 15, 2010 , respectively, at a differing orbit. Table 4 shows the basic information of these images.

As well known, using two SAR images acquired on the same relative orbit, the phase difference estimation (e.g. interferogram) can be estimated. This interferogram is a function of the local topographic elevation of the ground surface and the baseline distance between the satellite radar antennas.

\section{Results from the images before the impoundment}


The results of interpreting images from 2007 to 2008 (Fig. 7) indicate that it is feasible to apply D-InSAR to monitor the deformation of Guobu slope, although the slope is steep in general. The selected four images have good coherence, and we processed three pairs of interference images as shown in Fig. 7. The pairs of 20071209-20080124 shown in Fig. 7a and 20080124-20080310 shown in Fig. 7b show a high coherence, while the final pair of 20080310-20080610 shown in Fig. 7c has a comparatively low coherence. The deformation value at the platform corresponds to light green - light blue on the color bar. Therefore, we estimated that the deformation at the slope platform was quite small within the range of allowable error during the period from 10 March 2008 to June 10 2008. Namely, no obvious deformation occurred during this period before the impoundment.

\section{Results from the images after the impoundment}

To examine the slope deformation after the impoundment, we analyzed two pairs of images (20091214 and 20100129; 20091231 and 20100215). However, we failed to obtain useful results, because (a) there are many shadows and overlapping in the slope area along the riverside, and (b) these two pairs of images showed very low coherence, probably due to the fact that the deformation was simply too large for the D-InSAR.

\section{Results from ALOS-PRISM images}

In order to verify the results from D-InSAR analyses before the impoundment, and also to understand the slope deformation after the impoundment, we studied also high-resolution optical images. From optical imagery slope deformation can also be estimated through image processing applied to multi-temporal data. We used ALOS-PRISM images for the interpretation of slope deformation. Therefore, the phases of two images were made to match each other at first. And then through the multi-bands synthesizing method, the panchromatic-bands images in the later phase were put to the blue channel, and the panchromatic-bands images in the former phase were put to red and green channel. Finally, false-color images were synthesized by using these three-color channels on the basis of RGB principle. And the gray value of the area without deformation would be close to it before synthesis. In contrast, the area where deformation occurred will show blue or yellow color in different phases. By comparing and analyzing, the area with deformation can be identified and positioned accurately.

The processing results from the ALOS PRISM images during 14 November 2007 1 July 2008 are shown in Fig. 8 , where it can be noticed that on the crest part (the platform) of Guobu slope, the gray value after synthesis is close to that before the synthesis. This indicates that no obvious deformation occurred on this part during this period. The blue area on the toe part of the slope (within the green cycle) may result from the local failure accompanying the river incision.

Fig. 9 shows the synthesized results from the images of 1 July 2008 to 3 April 2009. The picture shows that on the platform of Guobu slope, the gray value after synthesis is close to the one before synthesis. This indicates that the slope deformation, if any, should be smaller than the value that could be detected by one pixel. Because the resolution of the images is $2.5 \mathrm{~m}$, we conclude that the deformation was less than $2.5 \mathrm{~m}$ during the period before and soon after the impoundment. It is also noted that the topographic change indicated by the yellow color resulted from the water level change due to impoundment. 
Fig. 10 presents the synthesized results from the images of 3 April 2009 - 22 May 2010. There are large areas of blue on the slope and platform. Taking the tension fractures on the crest of the slope as the scarp of the landslide, the whole slope showed remarkable deformation. Comparing two images of different phases in the same window enabled us to capture a maximum deformation of about 3 pixels (about $7.5 \mathrm{~m}$ ) on the leading edge of the platform, directing toward $\mathrm{NW} 280^{\circ} \sim 300^{\circ}$. The sliding direction is along It is noted that the vertical deformation of the landslide can also be identified by comparing the Google Earth images taken at different time. The images taken at three different dates $(2004 / 5 / 18 ; 2005 / 3 / 2 ; 2010 / 10 / 4)$ are available now on Google Earth for the platform (Fig. 11). The former two periods show now obvious difference on the cliff, but the recent one (2010/10/4) showed remarkably settlement along the cliff.

\section{Conclusion}

In this research, we used ALOS PALSAR and ALOS-PRISM images to examine the deformation of Guobu slope in differing time with the purpose of examining the relationship of Guobu landsliding and impoundment. Our conclusions are as follows:

(1) The radar images covering target area and meeting the interference conditions were collected from November 2007 to June 2008. The results of differential interferometry indicate that the deformation of Guobu slope during this period was very small.

(2) The image interpreting results from ALOS PRISM shows that no obvious deformation occurred on Guobu slope during the period from November 2007 (before impoundment) till April 2009 (one month after the impoundment).

(3) Though there is no radar image meeting the interference conditions in the target area from April 2009 to May 2010, the results of ALOS PRISM images indicate that Guobu slope had obviously deformed (with the horizontal displacement up to $7.5 \mathrm{~m}$ ) after the impoundment in April, 2009.

Finally, it is noted that detailed deformation monitoring on Guobu slope is continued, and proper countermeasures to lower the risk of catastrophic failure of this landslide are on discussion but have not been decided yet. This research provides a preliminary understanding and evidence of the deformation of this large-scale landslide due to the impoundment. Basing on recent monitoirng results, a maximum volume of landsliding mass has been estimated to be 70 million $\mathrm{m}^{3}$ approxiamtely, and the landslide could induce waves about $100 \mathrm{~m}$ high in the lake in worst case. Although the precision in the estimation of the landslide volume and the wave height needs to be elevated, the possible damage to the dam as well as to the downstream area will be devastating. A more detailed report on the monitored deformation data and an analysis of the failure mechanism will be provided in future once the data are allowed to published.

\section{Acknowledgements}

The research work described herein was funded by the National Nature Science Foundation of China under Grant No. 40772187. The financial supports are gratefully acknowledged. The valuable comments by Dr. Alexander Strom (Hydro Project Institute, Moscow), Dr. Hans-Balder Havenith (University of Liege), Dr. Yuepin Yin (China Geological Environment Information Site), are greatly appreciated. 
References

Antonello G, Casagli N, Farina P, Leva D, Nico G, Sieber AJ, Tarchi D (2004) Ground-based SAR interferometry for monitoring mass movements. Landslides 1:21-28.

Burgmann R, Rosen PA, Fielding EJ (2000) Synthetic aperture radar interferometry to measure Earth's surface topography and its deformation. Annual Review of Earth and Planetary Sciences 28: 169-209

Catani F, Casagli N, Ermini L, Righini G, Menduni G (2005) Landslide hazard and riskmapping at catchment scale in the Arno River basin. Landslides 2:329-342.

Colesanti C, Wasowski J (2006) Investigating landslides with space-borne Synthetic Aperture Radar (SAR) interferometry. Engineering Geology, 88(3-4): 173-199

Casagli N, Catani F, Ventisette CD, Luzi G (2010) Monitoring, prediction, and early warning using ground-based radar interferometry. Landslides 7:291-301.

Genevo is R, Ghirotti M (2005) The 1963 Vaiont Lands l ide. Giornale di Geologia Appl icata 1: 41 - 52, do i : 10. 1474/GGA. 2005-01. 0-05.0005

Fielding EJ, Blom RG, Goldstein RM (1998) Rapid subsidence over oil fields measured by SAR interferometry: Geophysical Research Letters 25:3215.

Galloway DL, Hudnut KW, Ingebritsen SE, Phillips SP, Peltzer G, Rogez F, Rosen PA (1998) InSAR detection of system compaction and land subsidence, Antelope Valley, Mojave Desert, California: Water Resources Research 34:2573-2585.

Kiersch GA (1964) Vaiont reservoir disaster. Civil Engineering 34: 32-39

Massonnet D, Rossi M, Carmona C, Adragna F, Peltzer G, Feigl K, Rabaute T (1993) The displacement field of the Landers earthquake mapped by radar interferometry. Nature 364:138-142.

Massonnet D, Briole P, Arnaud A (1995) Deflation of Mount Etna monitored by spaceborne radar interferometry. Nature 375: 567-570.

Massonnet D, Holzer T, Vadon H (1997) Land field, California, observed using SAR interferometry: Geophysical Research Letters 24:901-904.

Moller L (1964) The rock slide in the Vaiont Valley. Rock Mech Engng Geol 2:148-212.

Riedel B, Walther A (2008) InSAR processing for the recognition of landslides. Adv Geosci 14:189-194

Semenza E, Ghirotti M (2000) History of the 1963 Vaiont slide: the importance of geological factors.

Singh LP, vanWesten CJ, Champati RPK, Pasquali P (2005) Accuracy assessment of InSAR derived inputmaps for landslide susceptibility analysis: a case study from the Swiss Alps. Landslides 2: 221-228

Skempton AW (1966) Bedding-plane slip, residual strength and the Vaiont landslide. Geotechnique 16: 82-84 Ward SN, Day S (2011) The 1963 Landslide and flood at Vaiont Reservoir Italy. A tsunami ball simulation. Ital.J.Geosci. (Boll.Soc.Geol.It.)130(1):16-26.

Voight B, Faust C (1982) Frictional heat and strength loss in some rapid landslides. Geotechnique 32: 43-54

Yin Y, Zheng W, Liu Y, Zhang J, Li X (2010) Integration of GPS with InSAR to monitoring of the Jiaju landslide in Sichuan, China. Landslides 7:359-365

Yin Y, Wang H, Gao Y, Li X (2010) Real-time monitoring and early warning of landslides at relocated Wushan Town, the Three Gorges Reservoir, China. Landslides 7:339-349 
Table 1 ALOS PALSAR Image list

\begin{tabular}{|c|c|c|c|c|c|}
\hline Number & Image number & Data Mode & Orbit no & Frame & $\begin{array}{c}\text { Acquisition Date } \\
(\mathrm{y} / \mathrm{m} / \mathrm{d})\end{array}$ \\
\hline 1 & ALPSRP099860710 & FBS & 477 & 710 & $2007 / 12 / 9$ \\
\hline 2 & ALPSRP106570710 & FBS & 477 & 710 & $2008 / 1 / 24$ \\
\hline 3 & ALPSRP113280710 & FBS & 477 & 710 & $2008 / 3 / 10$ \\
\hline 4 & ALPSRP126700710 & FBS & 477 & 710 & $2008 / 6 / 10$ \\
\hline 5 & ALPSRP207220710 & FBS & 477 & 710 & $2009 / 12 / 14$ \\
\hline 6 & ALPSRP213930710 & FBS & 477 & 710 & $2010 / 1 / 29$ \\
\hline 7 & ALPSRP209700710 & FBS & 478 & 710 & $2009 / 12 / 31$ \\
\hline 8 & ALPSRP216410710 & FBS & 478 & 710 & $2010 / 2 / 15$ \\
\hline
\end{tabular}

Table 2 ALOS PRISM Image list

\begin{tabular}{|c|c|c|c|c|}
\hline Number & Image number & Orbit no & Frame & $\begin{array}{c}\text { Date } \\
(\mathrm{y} / \mathrm{m} / \mathrm{d})\end{array}$ \\
\hline 1 & ALPSMW096142875 & 140 & 2875 & $2007 / 11 / 14$ \\
\hline 2 & ALPSMW129692875 & 140 & 2875 & $2008 / 7 / 1$ \\
\hline 3 & ALPSMW169952875 & 140 & 2875 & $2009 / 4 / 3$ \\
\hline 4 & ALPSMW176662875 & 140 & 2875 & $2009 / 5 / 19$ \\
\hline 5 & ALPSMW230342875 & 140 & 2875 & $2010 / 5 / 22$ \\
\hline
\end{tabular}

Table 32007 -2008 ALOS PALSAR Image Pairs

\begin{tabular}{|c|c|c|c|}
\hline Master image & Slave image & Revisiting time/d & Baseline/m \\
\hline $\begin{array}{c}\text { ALPSR099860710 } \\
2007 / 12 / 9\end{array}$ & $\begin{array}{c}\text { ALPSRP106570710 } \\
2008 / 1 / 24\end{array}$ & 46 & 834 \\
\hline $\begin{array}{c}\text { ALPSRP106570710 } \\
2008 / 1 / 24\end{array}$ & $\begin{array}{c}\text { ALPSRP113280710 } \\
2008 / 3 / 10\end{array}$ & 46 & 570 \\
\hline $\begin{array}{c}\text { ALPSRP113280710 } \\
2008 / 3 / 10\end{array}$ & $\begin{array}{c}\text { ALPSRP126700710 } \\
2008 / 6 / 10\end{array}$ & 92 & 722 \\
\hline
\end{tabular}

Table 42009 -2010 ALOS PALSAR Image Pairs

\begin{tabular}{|c|c|c|c|}
\hline Master image & Slave image & Revisiting time /d & Baseline /m \\
\hline $\begin{array}{c}\text { ALPSRP207220710 } \\
2009 / 12 / 14\end{array}$ & $\begin{array}{c}\text { ALPSRP213930710 } \\
2010 / 1 / 29\end{array}$ & 46 & 688 \\
\hline $\begin{array}{c}\text { ALPSRP209700710 } \\
2009 / 12 / 31\end{array}$ & $\begin{array}{c}\text { ALPSRP216410710 } \\
2010 / 2 / 15\end{array}$ & 46 & 572 \\
\hline
\end{tabular}




\section{Figures}

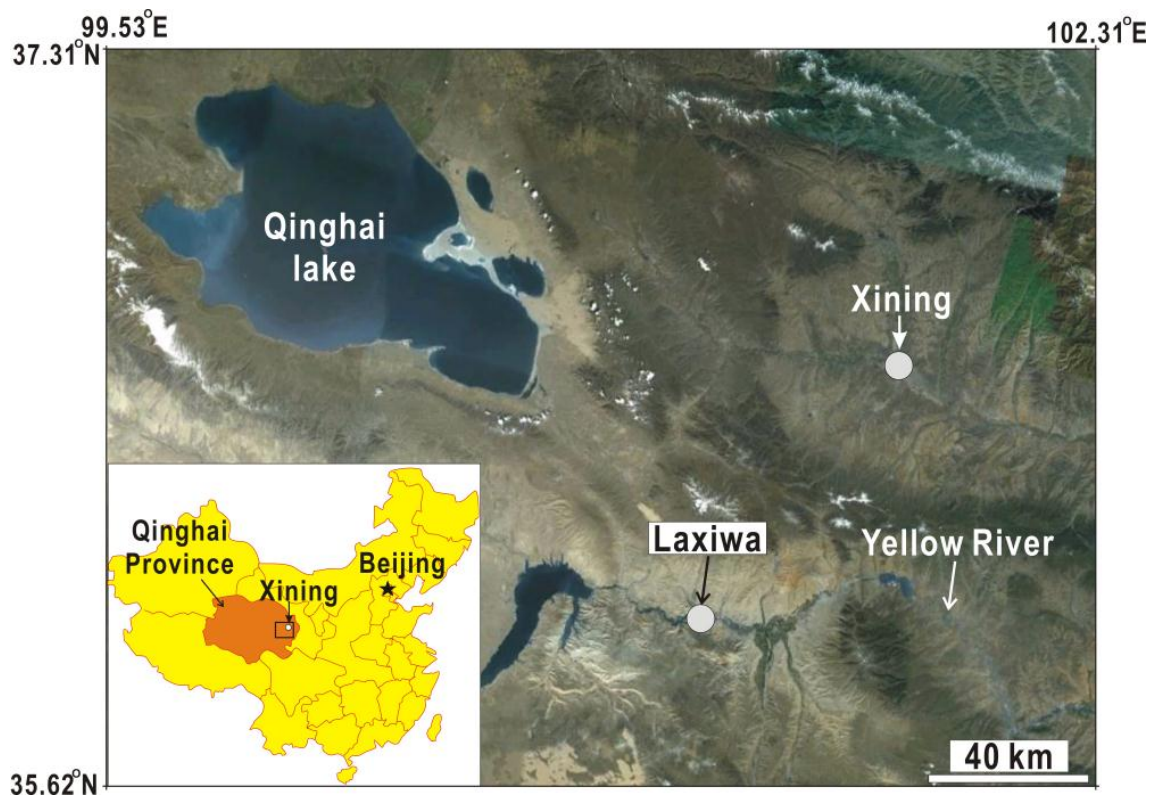

Fig.1 Location of Laxiwa dam site. Photo and coordinates are from Google Earth.

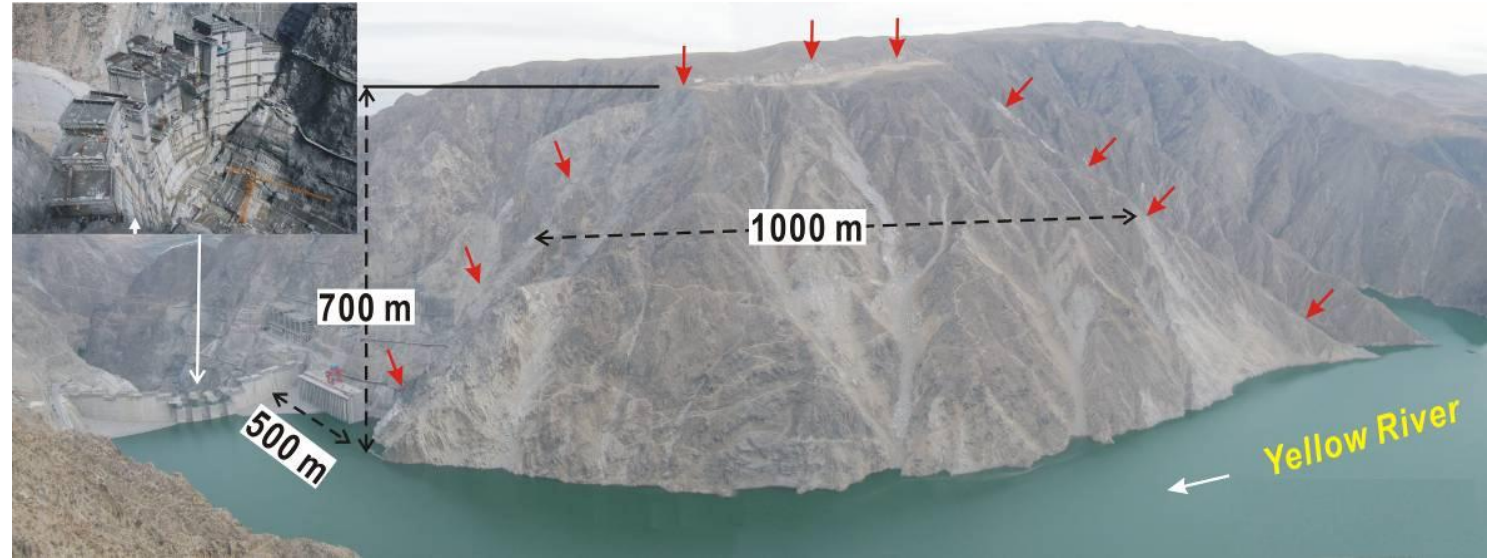

Fig.2 View of Guobu slope on the upper stream of Laxiwa dam after impoundment (Photo on 2010/1/14). Arrows show the boundary of the landslide 


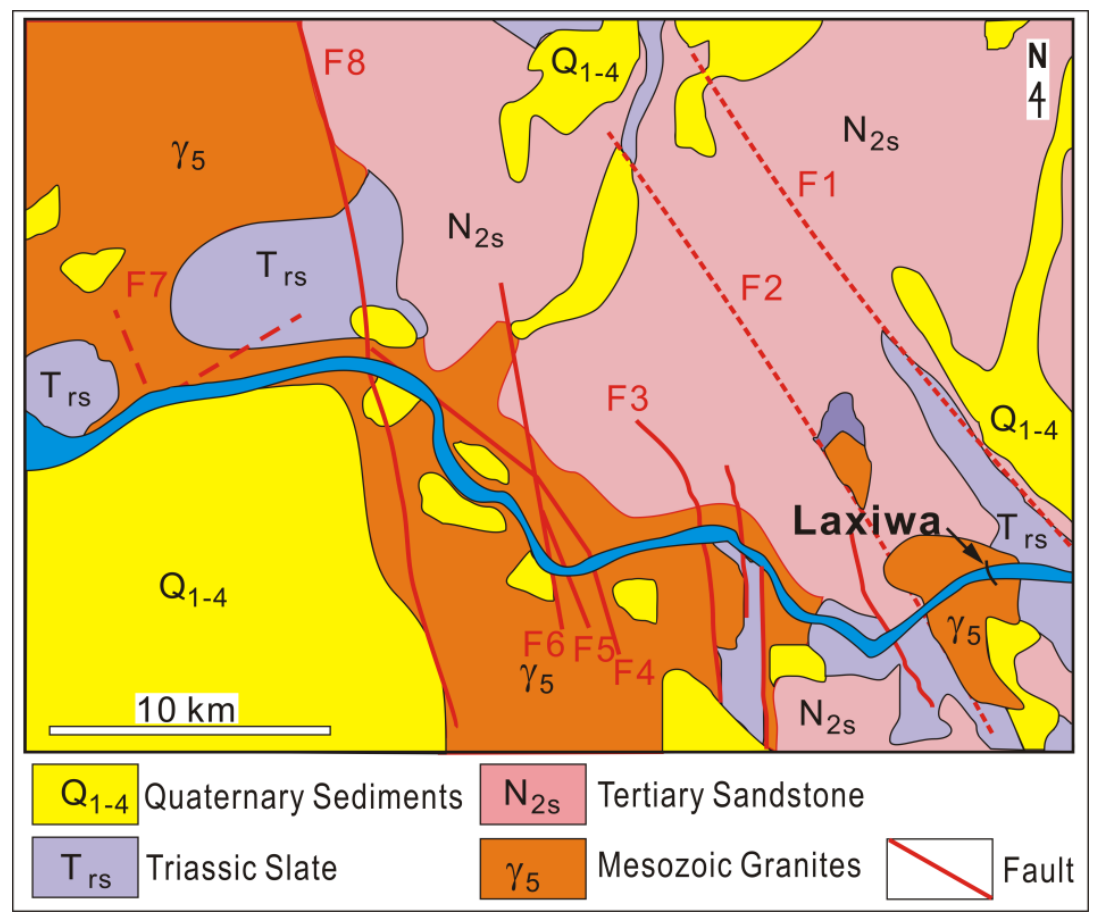

Fig.3 Geology map of Laxiwa dam site area

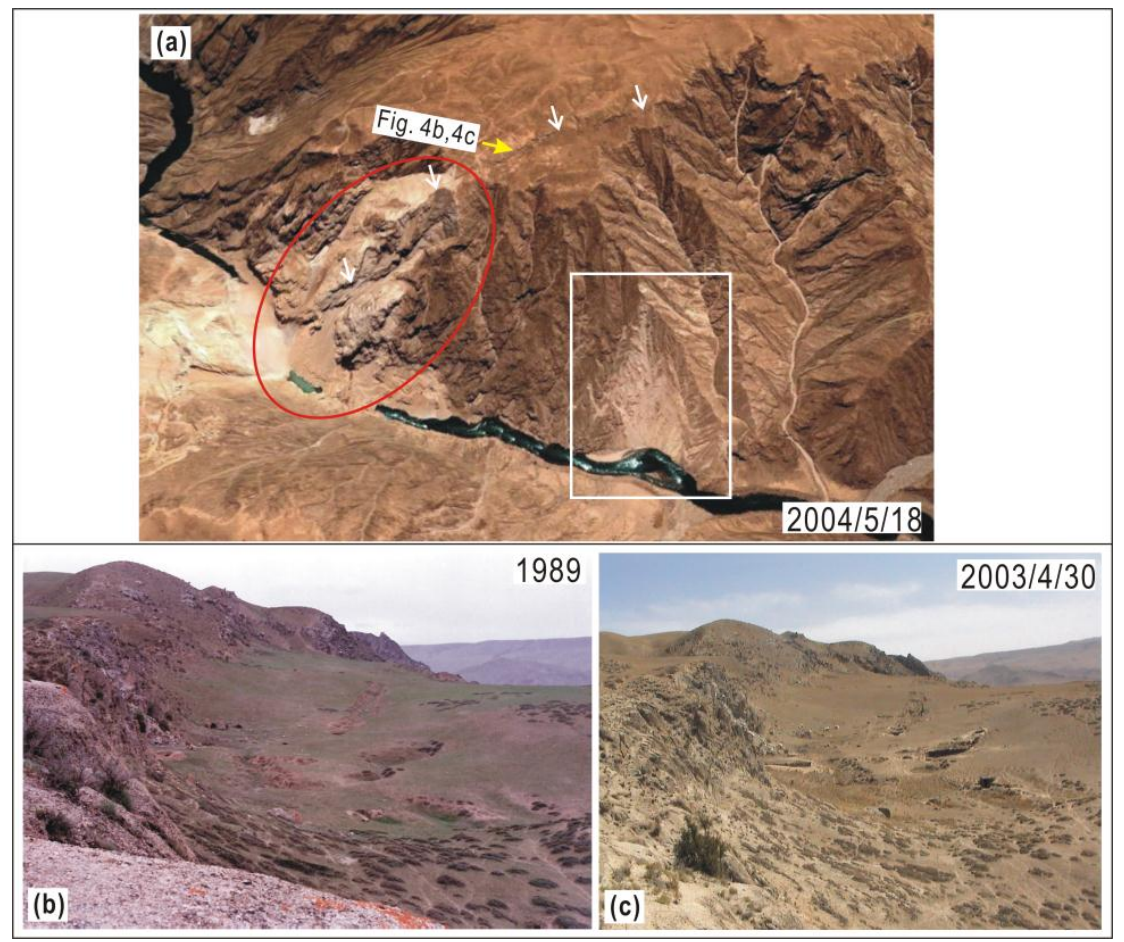

Fig.4 Oblique view of Guobu slope(a) from Google Earth, and the views of crest of Guobu slope at different time (b, c). 

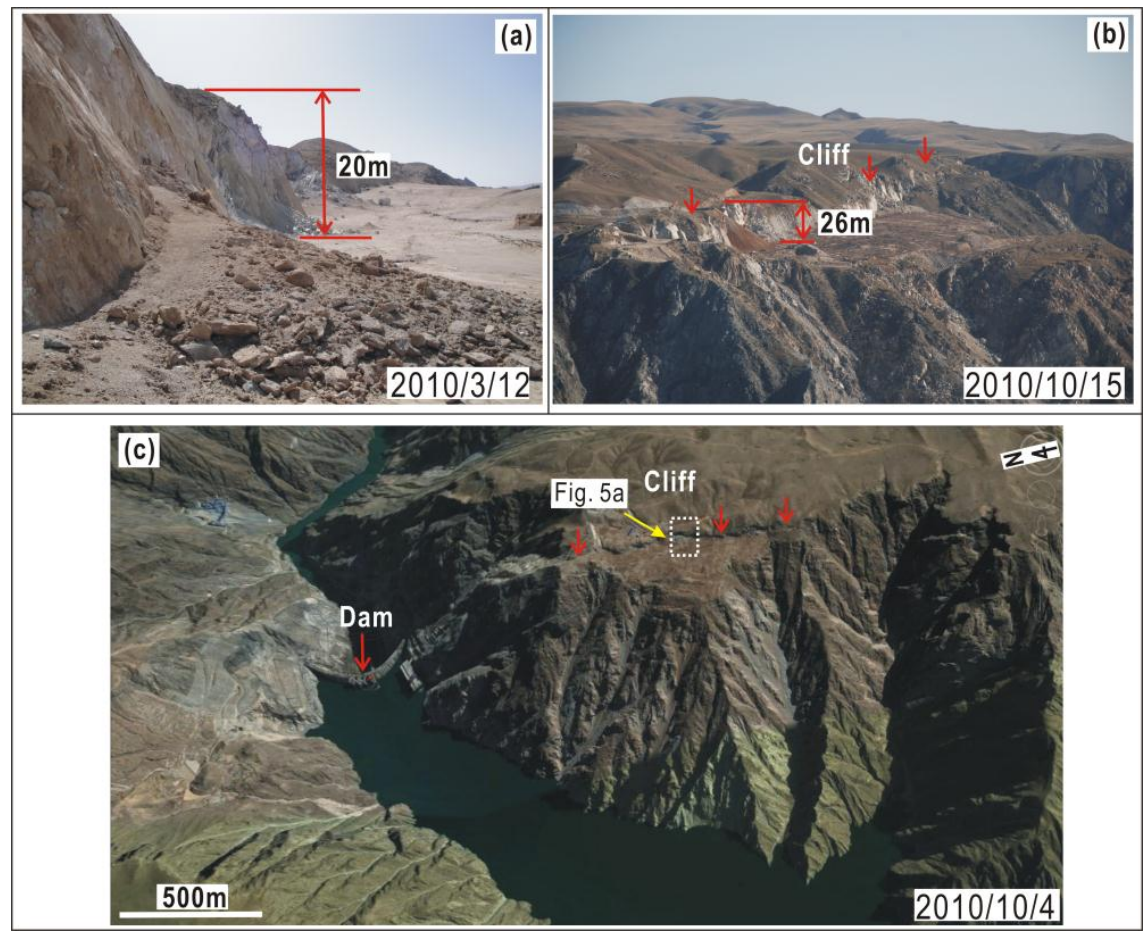

Fig.5 Deformation on the crest of Guobu slope after the impoundment.

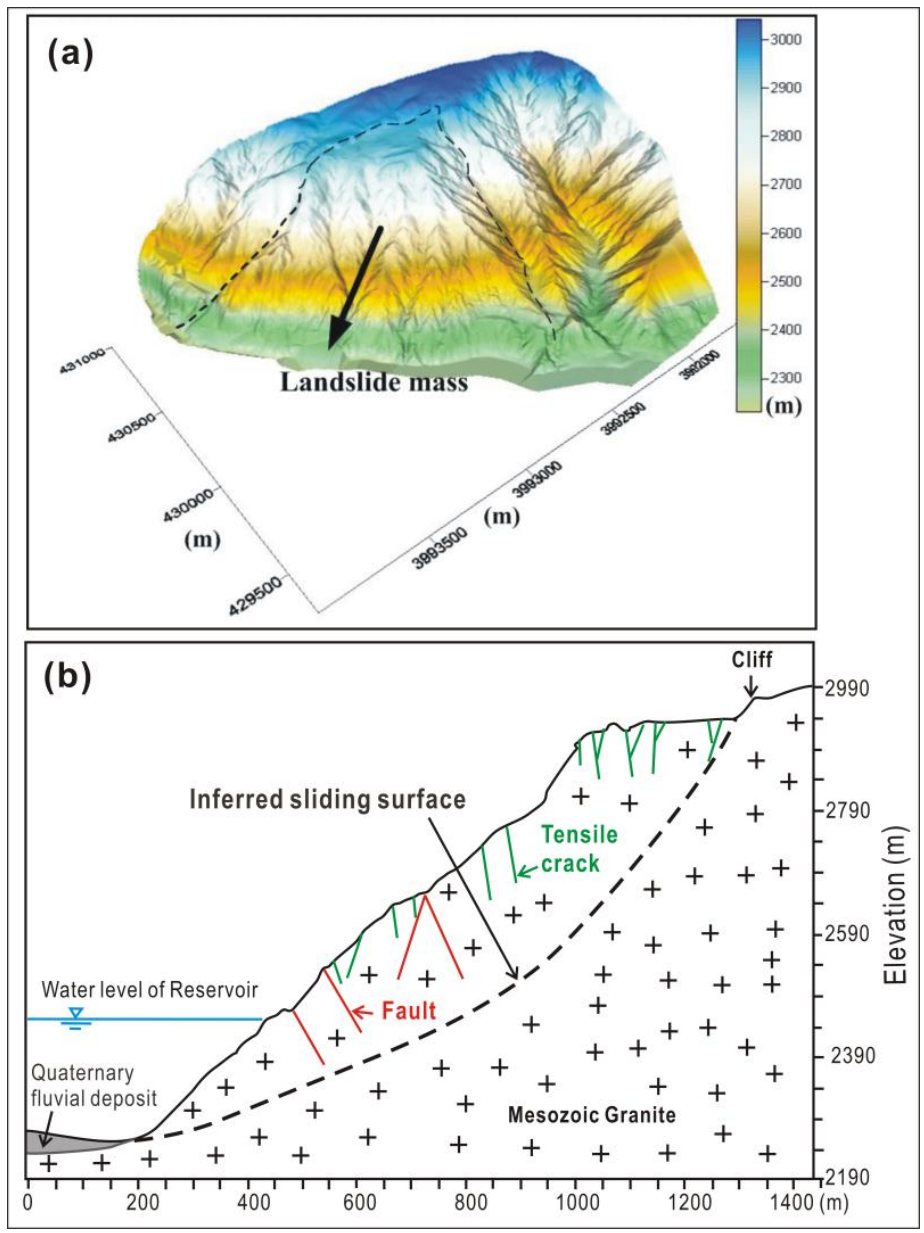

Fig.6 (a) Topography of Guobu slope area (a), and (b) longitudinal section along line a-b in Fig.6a 


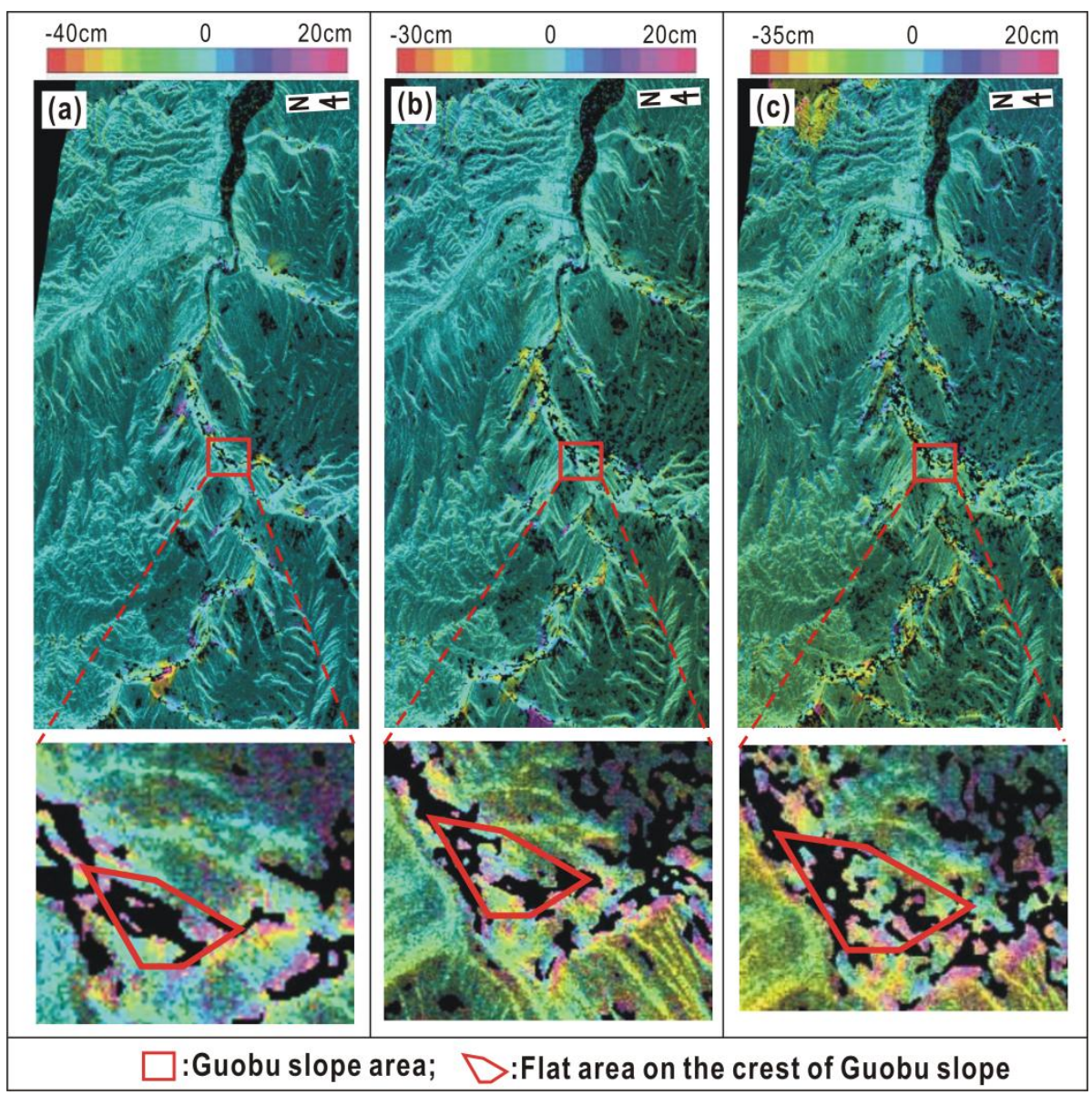

Fig.7 Interpreted deformation for different periods. (a) For the period of 2007/12/9 to 2008/1/24; (b) for the period of $2008 / 1 / 24$ to $2008 / 3 / 10$; (c) for the period of $2008 / 3 / 10$ to $2008 / 6 / 10$

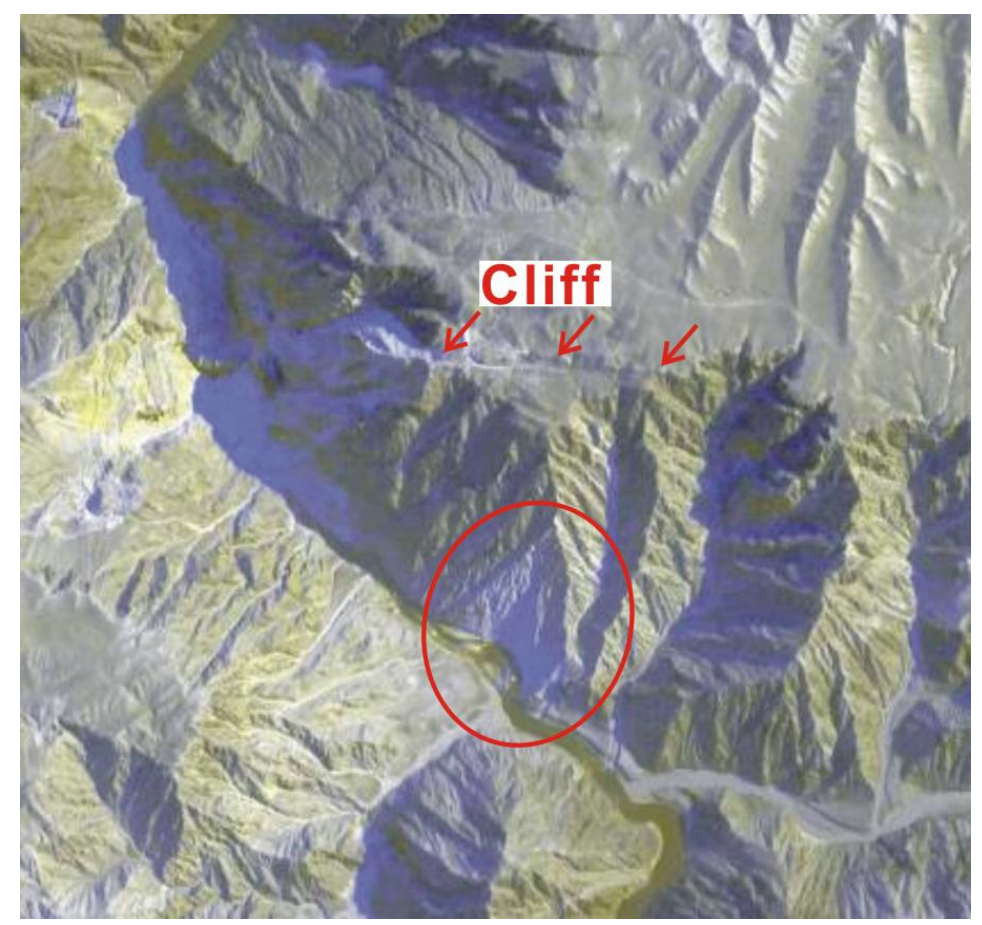

Fig.8 ALOS-PRISM image interpreting results for the period of 2007/11/14 to 2008/7/1 


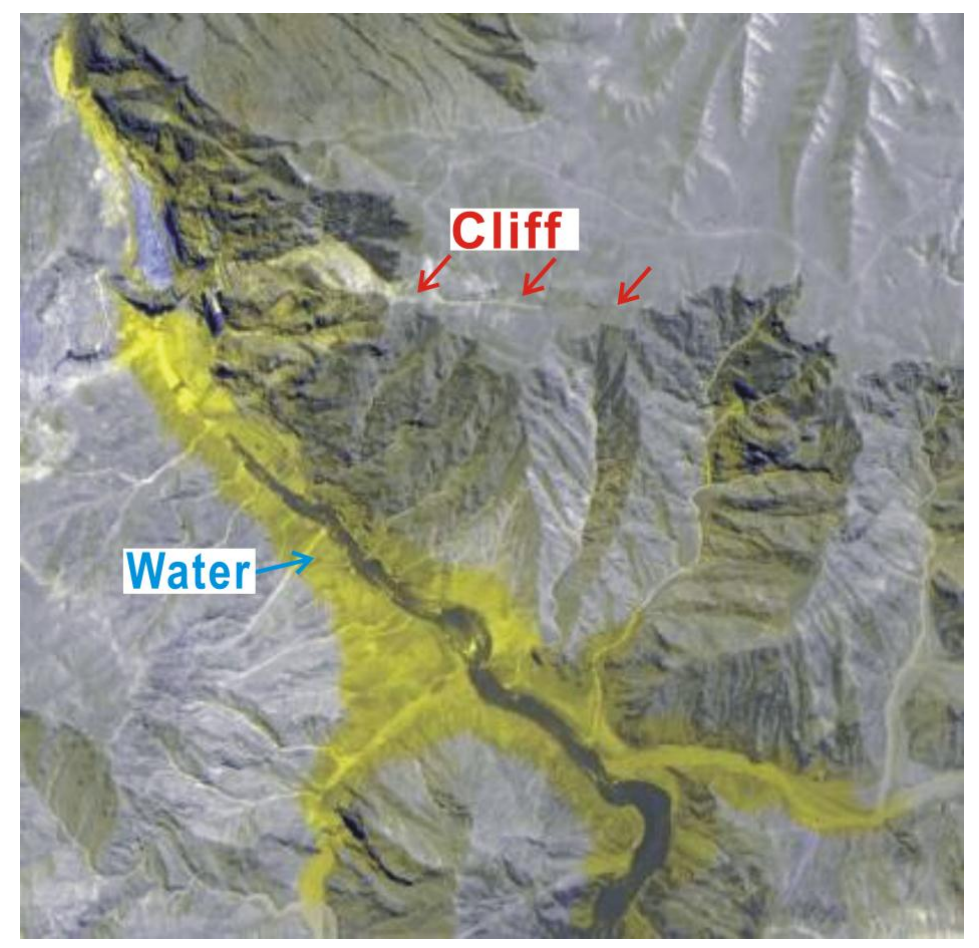

Fig.9 ALOS-PRISM image interpreting results for the period of 2008/7/1 to 2009/4/3

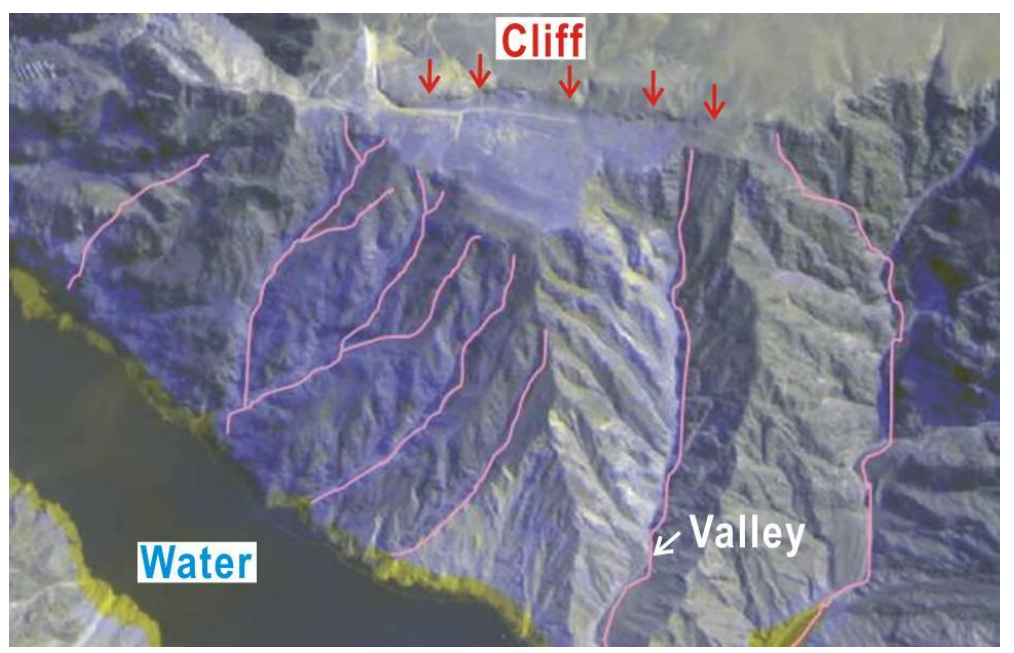

Fig.10 ALOS-PRISM image interpreting results for the period of 2009/4/3 to 2010/5/22 

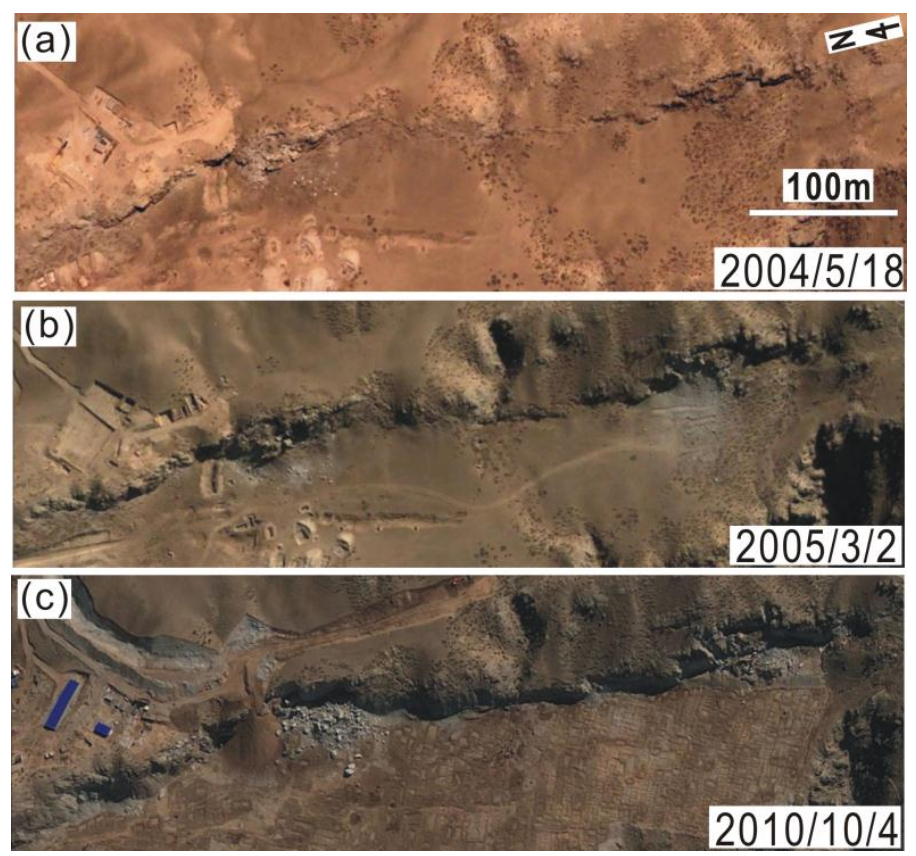

Fig. 11 Google Earth images of the cliff on the crest of the landslide at different dates 
Figures

Fig. 1 Location of Laxiwa dam site

Fig. 2 View of Guobu slope on the upper stream of Laxiwa dam after impoundment (Photo on January 14, 2010). Arrows show the boundary of the landslide.

Fig. 3 Geology map of Laxiwa dam site area

Fig.4 Oblique view of Guobu slope(a) from Google Earth, and the views of crest of Guobu slope at different time (b, c).

Fig. 5 Deformation on the crest of Guobu slope after the impoundment

Fig.6. (a) Topography of Guobu slope area (a) , and (b) longitudinal section along the line connecting point 'a' and 'b' in Fig.6a.

Fig. 7 Interpreted deformation for different periods. (a) For the period of 2007/12/9 to 2008/1/24; (b) for the period of $2008 / 1 / 24$ to $2008 / 3 / 10$; (c) for the period of $2008 / 3 / 10$ to $2008 / 6 / 10$

Fig. 8 ALOS-PRISM image interpreting results for the period of 2007/11/14 to 2008/7/1

Fig. 9 ALOS-PRISM image interpreting results for the period of 2008/7/1 to 2009/4/3

Fig. 10 ALOS-PRISM image interpreting results for the period of 2009/4/3 to 2010/5/22

Fig. 11 Google Earth images of the cliff on the crest of the landslide at different dates 